\title{
Missing PARADOXES AND THE EVIDENTIAL NATURE OF THINGS; MATERIAL OBJECTS IN A Cross-cultural Perspective
}

\author{
Bente Wolff
}

"[The] Father brought salt with him, he poured it on the hands and [the village people] tasted it. He gave them rice, and they thought it was ants' eggs. He gave them soap, and they cooked it. When they took it out [of the pot] it was melting. And he gave them boots, and they thought it was mermaid's' legs, so they cooked it. After cooking, they took it out to eat it, but it was really hard [so] they said: «the mermaid's leg is too hard to eat!n

This story is about the first white missionaries in the Mekeo village Eboa in lowland Papua New Guinea. I heard it told by the clan chief Opu Ame in 1991. As always when this story was told, it caused great amusement among those listening. It describes how the grandparents of today's villagers had their first inexperienced encounter with the white people's things at the turn of the century.

The local description of how the villagers were unable to use the foreign goods for their intended purposes seems familiar. It seems to accord with an idea commonly held among Westerners of a contradiction between western products and people living in what is often called tribal or traditional societies. We shall, however, see later that the story of strangeness and inexperience is certainly not the only way in which the Mekeo describe their relationship to imported products. These and other examples from Mexico, Africa, and Europe are presented in order to shed light on some of the implicit expectations we as Westerners may often have of certain objects."

Rather than trying to define some general principles of classification behind these expectations and discuss how they are actually expressed in museum exhibitions,
I intend to let the examples speak for themselves. It is my aim simply to provide some cases that will provide "good thinking material» when considering future 
108 ways of representing other cultures in museums.

First I should clarify what I mean by saying that we in the West often perceive a contradiction between familiar objects and far-away people. This contradiction is not just a matter of realizing differences between the customs and technologies in various types of societies. It is part of a wider distinction between a "them» and an «us». Material objects play an important role in maintaining this differentiation, since we tend to identify various cultural traits with certain objects, e.g. dress. This identification between objects and social life forms is epitomized in the museum, but it is a general cognitive mechanism that also exists outside the museum classification system. We immediately take note of "our» objects when we see them used by "the others". Whether regarded as depressingly disruptive of indigenous cultures or as comic «anachronisms" the objects somehow appear paradoxical in the foreign context. This perceived contradiction between the Other and "our" things is clearly expressed in a well-known type of advertisement that catches the eye by presenting, e.g., a NorthAmerican Indian wearing a feather headdress in an advertisement for a car. The fact that such pictures do in fact draw our attention confirms that the ideational contrast is there in our heads.

\section{YUCATAN, MEXICO: MISSING PARADOXES}

It is not only as unreflecting consumers that this contradiction exists in our minds, but also as social scientists trained in analyzing foreign cultural settings. The
Danish anthropologist Peter Hervik has given an example of this from the Mayan village he studied in Mexico (1992: 71-2). $\mathrm{He}$ and his colleague asked a local amateur photographer to take photos of the everyday life of his village as seen by the photographer himself. This viewing of village life through native eyes worked well, except when the photographer was asked to take pictures of what the anthropologists perceived as "paradoxes», i.e. "where the traditional Mayan culture 'collided' with cultural elements [the anthropologists] normally associated with modern Western goods" (ibid.: 71). What the anthropologists had in mind were pictures of, e.g.,

thatched Mayan houses with modern electrical stoves $[\ldots]$, traditional houses with five meter TVantennas - some without televisions in the house [...], people who had electrical kitchen utensils, but no electricity (ibid. 72)

This photo project, however, failed because the photographer was unable to take the required photos. This was not because the village lacked such "paradoxes", but because the photographer did not view them as such. To him a thatched roof and an electric stove did not constitute a paradox. The paradoxes were only present in the eyes of the anthropologists whose original expectations of the Mayan Indians were shaped by "historical reading and the physical presence of ruins from the preColumbian era» (ibid. 72). This incident brought an awareness to the Danish anthropologist that we tend to treat other cultures as "organic entities», i.e. wholes in which new elements are regarded as destructive of the imagined cultural totality. 


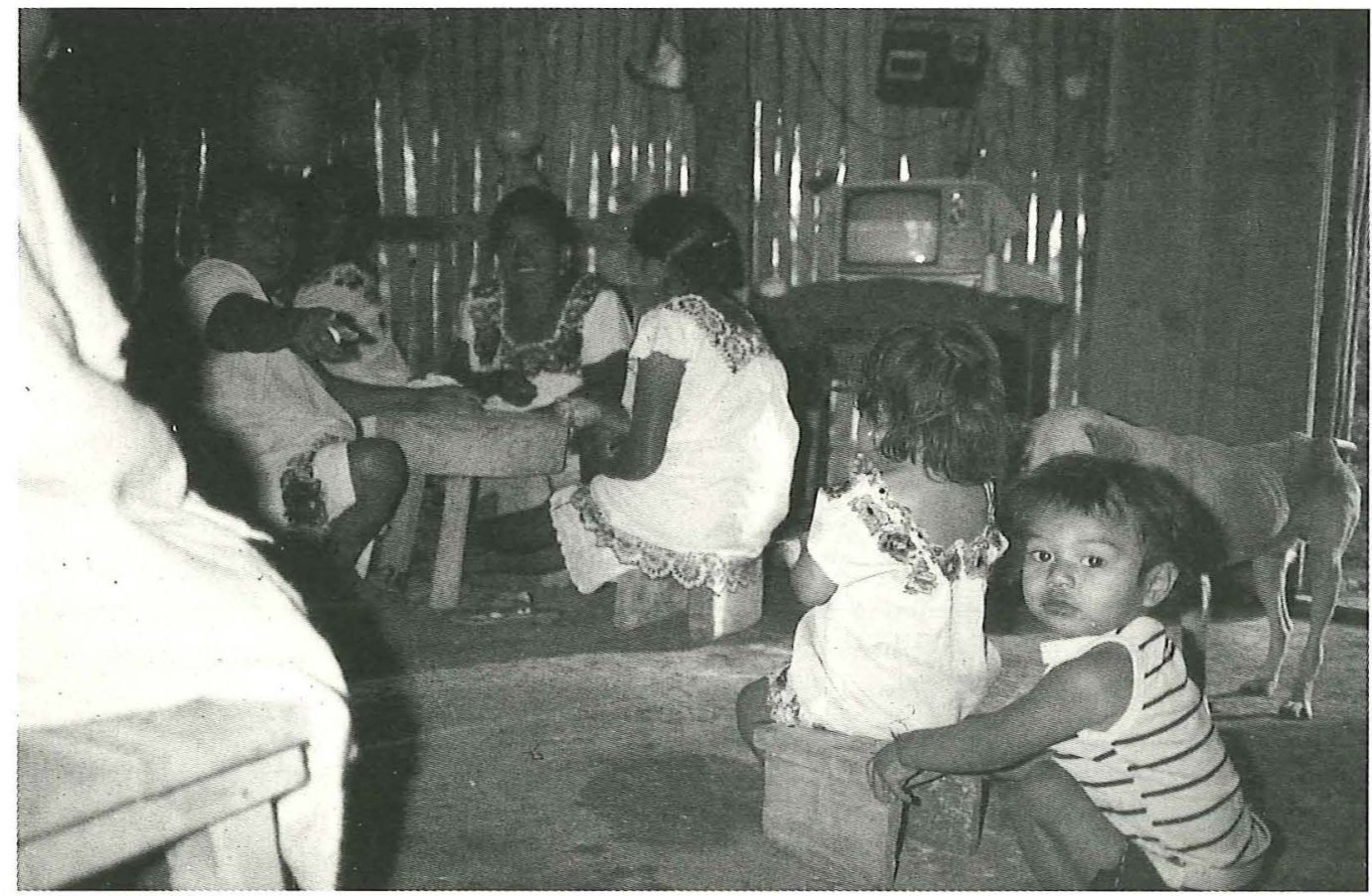

An example of the "paradoxes" that the anthropologist, but not the Mayan photographer, noted: In a house made of wooden rods erected on the bare ground, Maya women make tortillas while watcing a TV-program on moon landings. Xuilub village 1989, Yucatan, Mexico. Hans Henrik Philipsen phot.

The Mayan example introduces two themes that I would like to take up here. The first is the fact that the Mayan villagers did not view the imported things as in any way contradictory to their own way of life. I want to use the following cases from Papua New Guinea and Congo to show how imported things are readily incorporated into traditional cultural concepts and how such objects are not necessarily perceived as being inherently foreign or strange by the local people.

The second theme which I call "the nature of the thing" is taken up in the last section of this essay and reflects on how material objects seem to hold a certain inherent meaning for us, to appear unambiguous and self-evident. As a modern social researcher the Danish anthropologist in Mexico did not of course subscribe to a unilinear perspective of cultural evolution in which other peoples are regarded as living examples of earlier phases of our own cultural evolution. Yet he found that initially he still had some clear, pre-figured ideas about the meaning of various material objects in the village: pyramids were Mayan, although Mayans stopped building them long ago, TV aeriels were un-Mayan, although Mayans buy them and use them. Instead the TV aeriels were viewed by the anthropologist as something 
110 inherently Western, although - I would guess - they were more likely to come from the East, since, as we all know, this is where most electronic goods are produced today.

\section{PAPUA: KNOWLEDGE OF THE ANCESTORS}

If we now return to the Mekeo villagers of Papua New Guinea and investigate more deeply their view of imported goods, we find that the contrast between the objects their ancestors used and those of the white people is not as clear cut as was first indicated by the story that opened this essay. What is not told in this story, but in other more secret stories, is that the kinds of goods that are today being imported from overseas originally belonged to their ancestors and their own land:

[That mountain ${ }^{2}$ ] is the place where A'aisa landed his Ark carrying all the races of people living in Papua New Guinea, and also the horses, the ships, cows, trucks, and all the other animals. From there [the ancestors] started to move southeast towards the place where we are now living.

This story from Eboa village was told to me by the sorcerer Kafo Piau. It explains how the goods originally belonged to the ancestors of the present day Mekeo. Long before the time of British colonization A'aisa, the Mekeo god, had brought the goods to the land of the Mekeo from where they later spread to the white people. ${ }^{3}$ There is no single explanation of how the things spread, but a reason commonly given is that the local people did not take proper care of some god or spirit-person possessing some particular old and powerful knowledge.
Electricity is, eg, understood as the knowledge of A'aisas younger brother, Isapini. Isapini's knowledge is the easy way of doing things without hard work. A'aisa considered Isapini's way far too easy and sent his younger brother away, in order to prevent people from being lazy. Isapini must have gone to the white people, the villagers reckon, because the whites now are the ones to have the easy electric (literally "power") way of doing things by just pushing a button and getting everything they need from a shop. Without Isapini's knowledge the unfortunate Mekeo are not able to get their food, build their houses, or complete other basic tasks without hard work and sweat - although some ancestoral knowledge is still held by most people and considered a necessary supplement to manual work.

My aim here is not to compare the Mekeo stories to our own explanation of the origin of things, in order to determine which explanation is more true in an objective sense. What is relevant in this context is that the imported goods hold a totally different meaning for the Mekeo than would be expected by most westerners. Here I want to focus on two aspects of the local meaning expressed in the stories.

First, despite their somewhat exotic or "fairy tale" character, the stories of how the things were lost clearly refer to an extremely uneven distribution of material goods and income opportunities between the indigenous population on the one hand and foreigners on the other. Interpreted not as "stories" in our sense of the word (i.e.made up and untrue), but as serious reflections on experienced inequity and poverty, the stories describe a political and economic system in which foreigners 
and naturalized immigrants own every business larger than a market stall. In this system the indigenous population is extremely disadvantaged in terms of educational and career opportunities, despite Papua New Guinea's status as an independent nation since 1975 .

Secondly, as was implied in the story of Isapini's knowledge, such stories reveal a local cultural model in which the desired goods are understood as material manifestations of powerful knowledge. In other words the ideational scheme follows this pattern: things $=$ power $=$ knowledge, $\mathrm{a}$ model which is also common in other Melanesian societies. Just as common to the Melanesian peoples is the way that this powerful knowledge is associated with the ancestors and the land of the clan, as we saw it in the story of the A'aisa's Ark. ${ }^{4}$

The feeling of being socially and economically disadvantaged combined with the specific definition of power as materialized (i.e.objects) ancestoral knowledge is an implicit cultural rationale behind the so-called Melanesian cargo cults. In these cults Melanesians have emulated the gestures of white people and made copies of their

Another "paradox"? The holy virgin wearing a traditional Mekeo feather headdress is carried in procession in Eboa village where Pepsi streamers and valley ball uniforms decorate the village plaza. Papua New Guinea 1991. Bente Wolff phot.

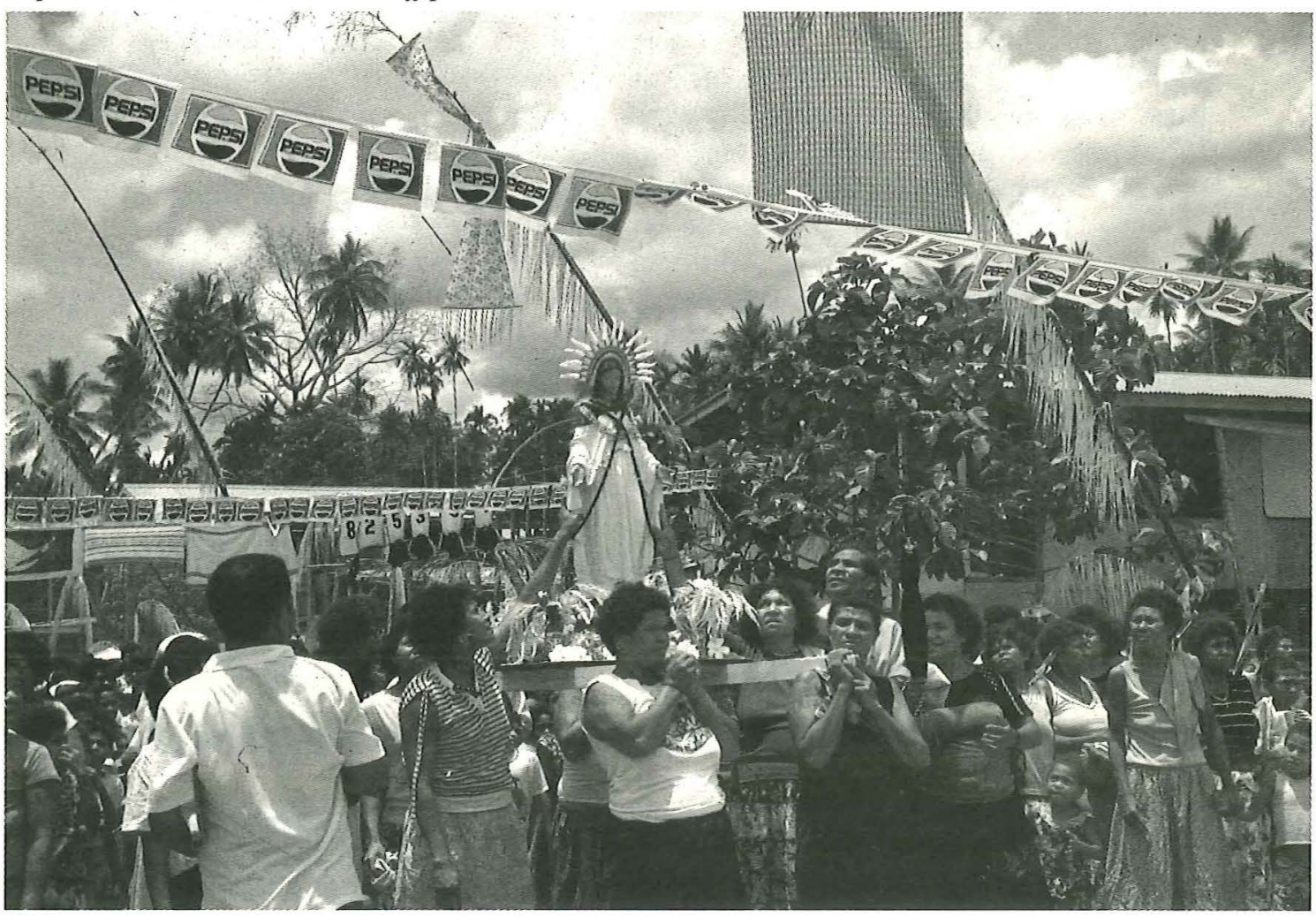


112 clothes and other possesions in order to bring back the lost ancestoral knowledge.

A recent example of this kind of attempt to achieve power was the so-called Powerhouse which took place in Eboa village over some months in 1988. The members were a small group of men descended from chiefs, and because of its exclusive character the groups' activity should perhaps be termed a cargo $\operatorname{club}$ rather than a cargo cult.

According to one of the club members and his wife in 1991, the participants had endured weeks of seclusion and almost complete abstinance from food, except for large amounts of raw chili and ginger. During the fasting period they studied various American books and other mailorder purchases. The books were Californian and covered subjects such as psychic power and mysticism, telling the future by reading the palm and eyes, as well as Rosicrusianism. The club house also contained figure-heads of the «ancient Egyptian Pharao and Hematon [who] are Gods or something». These items, presumably 5 from some Californian New Agers, were supplemented with what appears to be more classical American conmanship in the form of a so-called «Business Opportunity Club» to which the participants sent several thousand Kinas (1 Kina is worth about 1,2 US\$).

At first glance the Powerhouse may look as completely un-Melanesian, a total mish-mash of foreign elements. This is only so, however, if one focuses on the objects themselves and not on the way they were used and for what purpose. Seclusion and the consuming of hot things such as chili and ginger instead of food are customary ways in which to achieve power and reduce fear that were also practiced at the time of colonization. The purpose of the whole thing was to be able to enter a secret cave in the mountain O'opo. Another cave in this mountain was used as a burial site for the dead in the olden days. The inside of the secret cave was said by the club members to be filled with a glittering light and it contained a statue of a local god guarded by a huge python snake. One of the most powerful village sorcerers was known to possess one of the statue's petrified fingers. The activities in the powerhouse were meant to give the participants the strength and courage to enter the cave where they would find all the various powers stored: «Inside you can get what you want: ungaunga (sorcery to kill by sickness and snakebites), menga (formulas for gardening, hunting, etc.), iso (knowledge for fighting), and faia (knowledge for weakening your opponent in fighting, games, and gambling)».

What thus becomes clear when studying the local meaning of imported things in the Papuan context is that they do not represent a breakaway from certain traditional ways of thinking. The Powerhouse was not a culture-confused, fragmented way of taking bits and pieces of everything foreign and therefore fancy. Instead it was a matter of getting together some of the knowledge that was considered to have once been held by the ancestors but which had been lost, in an attempt to enter what is still considered the centre of powerful knowledge: the cave in the mountain of the dead ancestors. Thus the reasoning behind the Powerhouse project is both typically and traditionally Melanesian. Imported things are considered manifesta- 
tions of ancestral knowledge just like locally raised pigs, garden produce, sorcery, and love; the difference lies in the type of knowledge that is used for making various things, not in the origin of the objects or the principle of their creation. By focusing narrowly on the foreign origin of imported things when we meet them among the Papuans we tend to take the things as paradoxical evidence of cultural change. To the Papuans imported goods are other kinds of desirable things, but they are not perceived as being anything foreign that might threaten their customary way of living.

I am not in any way asserting that change in cultural models has not taken place in all kinds of societies over time, or that colonization has had no cultural impact on the colonized. What is interesting in a museum context, however, is to understand how little such change has to do with the incorporation of new material objects. This, I believe, is an important subject to reconsider if one is engaged in interpreting and documenting (i.e.researching) or representing (i.e.exhibiting) the life of others through the use of material objects.

The objects can be part of a strengthening of the tradition as when a new generator is bought collectively by the clan members to provide power for coloured light bulbs on the chief's platform. Or they can be part of a change in tradition as when a man buys a deepfreeze in order to keep his food to himself instead of sharing it as custom prescribes. The deepfreeze, the generator, and the CalifornianEgyptian statuettes, would seem strange representatives of a Papuan people in a museum display. Nevertheless, all of these things are as common to the Mekeo as are bride-price valuables made of dogs' teeth and birds' feathers. These latter may fit better into our prototypical image of Papuans, but they are also import products, as the Mekeo have hardly any crafts traditions themselves. So what would constitute appropriate objects to collect and display if one were to make an exhibition on the Mekeo? There is probably no single, listable answer to this question, but there must surely be several practical answers in the form of possible exhibitions. The main challenge is of course that it is no longer considered possible to identify a particular culture by a specific set of material objects. This is not simply because the same kinds of objects are now being used all over the world. It is also because of an increasing realization of the fact that even distinctive objects, products of a particular local crafts tradition, may well have shifting functions and meanings over time as the next example from Congo will indicate.

\section{CONGO: POWER FIGURES CHANGING SIGNIFICANCE}

The West and Central African section of the exhibition People of the Earth in the Danish National Museum comprises objects that are typically used to represent Africa in ethnographic museums. These objects are, e.g., Benin bronzes, an army leader's dress from Ghana, various masks, ceremonial weapons, and several power figures or fetishes.

Such power figures, minkisi (sing. nkisi), originally came from the French and Belgian Congo states, now the Republic of Congo and Zaire respectively. Minkisistatuettes - the small wooden human figu- 
BENTE WOLFF

114 res with nails, mirrors, and feathers could be called an essential African object in a museum context. Each statuette is equipped with a parcel of powerful substances made of leaves, teeth, nails, stones, and various other ingredients. This substance (bilongo) is where the nkisi-force, ie. the spiritual agent of the figure, is concentrated. The term nkisi refers to any kind of object containing nkisi-force, not only statuettes, but also bags, parcels, shells, etc, which contain similar powerful substances (Mac Gaffey 1991:5). Minkisi were believed to be able to detect and punish wrongdoers and to cure as well as cause diseases, a particular nikisi being related to a particular disease.

Ekholm Friedman (1991:139 ff.), by comparing colonial and pre-colonial sources, convincingly argues that the European colonization of Congo at the end of last century led to a fragmentation of previously existing public cults honouring the king and the common ancestors. Instead there evolved an abundance of more individual and experimental power-magics concerned with countering witchcraft as well as achieving personal health and wealth. Ekholm Friedman views this shift as an effect of European colonialism from about 1880 that lead to a breakdown of the previous centralized power structure of a divine kingdom as well as to a rapid spread of imported diseases causing death and sterility. In the first decades of colonialism the production of minkisi-figures increased considerably. Where they had earlier been fewer in number and had had their place in public space, such as the centre of the village, they were increasingly worshipped for personal projection and witch-hunting in smaller cults. The incre- ased production and specialization of $\mathrm{min}$ $k i s i$ in the early colonial era can be understood as desperate attempts to counter the many new diseases, locally ascribed to witchcraft (ibid. 141-2).

Seen in this light the many power figures in European museums from the colonial period may be said to represent a period of extreme crisis in Central African histo$r y$, an era.in which local people experienced a loss of political power, health, and fertility. Although the figures were known in pre-colonial times, their local role and meaning were constantly re-shaped by the specific historical circumstances.

In the eye of the museum visitor, however, the power figures may appear rather as examples of a long cultural tradition in which accusations of witchcraft and individual health and wealth had always been the main aspects of religious beliefs. The point that the increase in the production of minkisi and accusations of witchcraft were just as much a result of European colonization as of local beliefs is not something that will be evident to a European museum visitor looking at the figures. Of course an accompanying text can explain that these figures represent the break-down of a religious system rather than the long-term operation of the system. But it is important to note how such explanations will go against the initial perception of the object by the beholder, as the object immediately conveys a certain meaning to him or her. This meaning is seldom thought about, but seems plain and obvious, as an attribute of the object itself. The minkisi appear to be typical evidence of African tradition just as pyramids do of Mexican. 


\section{CONGO: INCORPORATION OF FOREIGN VITALITY}

With reference to the same seemingly evidential and inherent meaning of objects, the following example from present-day Congo will show that cultural continuity and viability can be just as difficult to represent through objects as can cultural change. What I will here use to exemplify a case of cultural continuity is what Ekholm Friedman calls "the Kongo principle that things from the outside are always better and stronger than things from the inside» (ibid: 141). This principle is significant if we want to understand the current consumption of European goods in the Republic of Congo.

This is not the place to go into details about how this principle of external power can be said to have been articulated during history. The common theme is, briefly stated, a belief that social as well as individual life is sustained from external sources. Material wealth and health - the two were and are considered to be firmly linked in Congo - must be obtained from such foreign sources. Ekholm Friedman has found that the term nkisi could be used to refer to the storehouse for European exchange goods (Güssfeldt 1888 in Ekholm Friedman 1991: 55). Thus we see an explicit link between Congolese power-substance and European goods, being two kinds of materialized power. This link is also represented by Congolese power figures having European coins as an ingredient in their powerful substance (one of these is in the Danish National Museum). ${ }^{6}$

In pre-colonial times the externally derived materialized life-force, e.g.in the form of imported items essential for bride price, would be channeled down through the social hierarchy of the kingdom. The king was the centre and apex of this hierarchy, his own power being described as foreign in the myths of his ancestors, the first kings who came as invaders. Today a similar concept of an external power centre from which materialized life-force can be obtained still exists:

Les sapeurs progress through a system of age grades that begins in Brazzaville with the acquisition of European ready-to-wear imports, and which then takes them to Paris where they accumulate, by any means available, famous designer clothes from France and (the highest-ranked) Italy at tremendous expense. An occasional return [is made] to Brazzaville [...] to perform the danse de griffes, with the great name labels that are sewn into the lapels of a jacket and displayed accordingly as part of the ritual of status (Friedman 1994: 105)

The term sapeur refers to the members of the Société des Ambianceurs et Personnes Elégantes (SAPE), a society in which young, socially marginalized Bacongo men without regular employment compete in elegance (Friedman 1994:147-66, Martin 1994: 423-4). Within the extremely hierarchical structure of the society the members are ranked strictly according to the value of their wardrobe and to whether or not they have gone through the initiation rite (l'aventure) in the form of a move to Paris as mentioned in the above quotation. The goal is to own a set of famousname haute couture clothes called la gamme (= "scale») (Friedman 1994: 107). Regular lightening of the skin with strong chemicals - often termed bilongo like the 


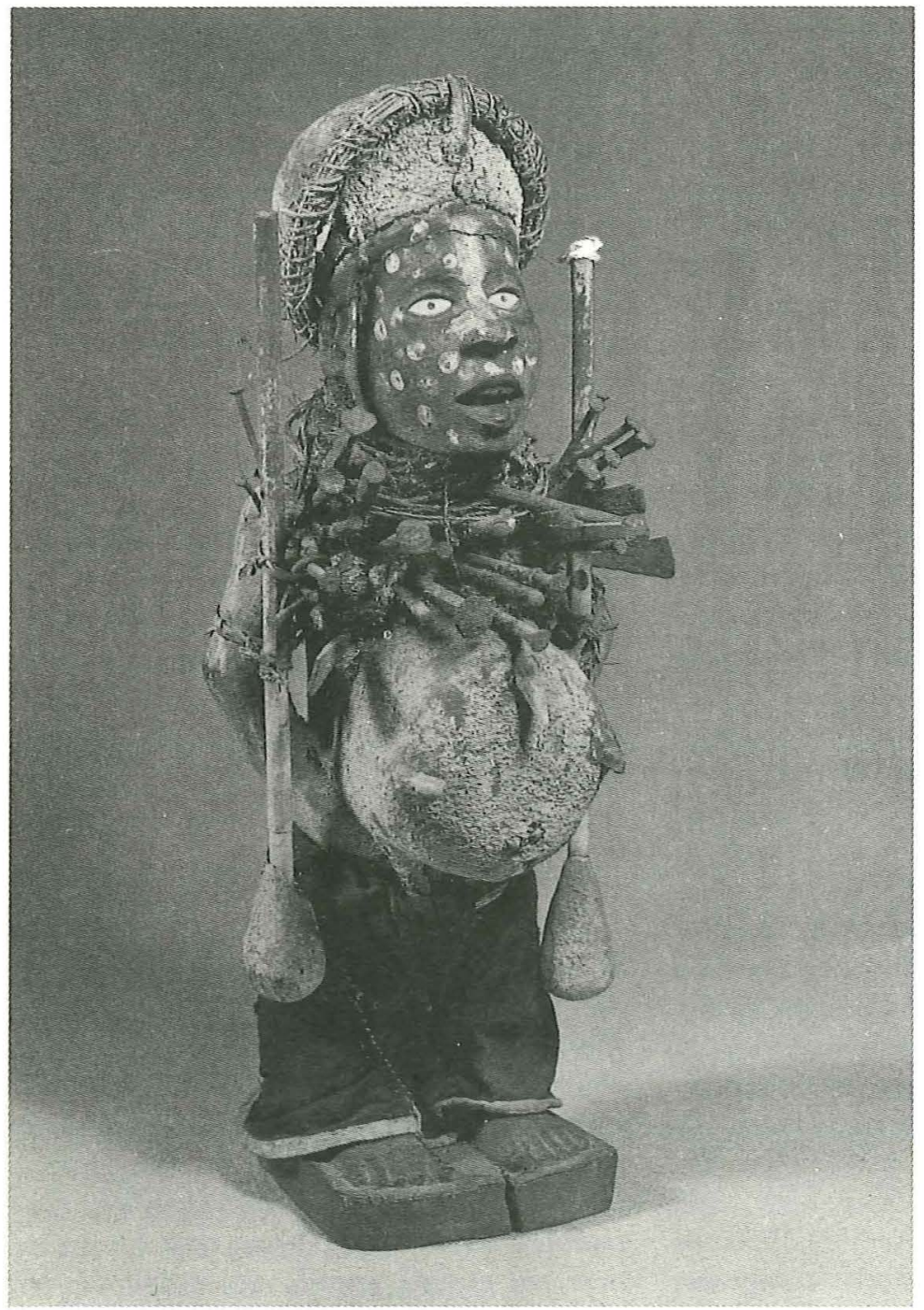

The essential African object or rather a product of European colonization? Congolese Nkisi (Zaire). The National Museum of Denmark, Department of Etnography Ga.58, acquired 1891. Kit Weiss phot.

powerful substance of the nkisi-is also an important part of becoming a sapeur.

This "cult of elegance" is clearly more than just a matter of fashion. The Sapeur phenomenon in its present form has evolved during a period of steadily increasing economic stagnation and one in which the
Bacongo have lost their earlier political influence to the Mbochi (Friedman 1994: 158). The conspicous extravangance of the sapeurs is a display of the personal and group power of Bacongo feeling deprived of all opportunities in the clan-like political party system. It is viewed as a chal- 
lenge and potential threat by those in the official political system as the cult members are basically attempting to gain power directly from the centre of power, i.e. Paris, without acknowledging the channels of the system.

Elegance as a political power manifestation is part of a more general cultural model in which appearance is viewed a true expression of a person. It is a model that differs from the one that has prevailed in the West in the modern era in which surface, in the form of clothes and make-up, has been regarded as false and unauthentic. This is not so in Congo (and other parts of Africa) where a person's wealth and health (i.e. his access to a power source), is believed to be immediately reflected in his or her appearance. This is not to say that the Congolese do not experience an inner, invisible side of themselves, but to stress the point that the appearance of a person is not considered a faked or unauthentic surface. The appearance is the true person, and thus, the welldressed person is the powerful person. ${ }^{7}$

Thus the Congolese elegance cults further illustrate a problem for an ethnographic museum whose objectives are «to add to the knowledge and understanding of foreign cultures" and "to create an understanding of people with a different cultural background" (cited in the 1995 international evalution of research activities in The National Museum of Denmark p. 54).

As a modern expression of a long-existing concept of vitality, wealth, and political power the designer clothes would be an object well suited to represent the Congolese culture of today in a museum. The Congolese use of European clothes as a power manifestation goes far back in 117 history. As early as in the 16th century the higher classes of the Kongo kingdom where reported to dress according to European fashion and also at that time the dress code was an important means of social distinction (Pigafetta 1591 in Friedman 1994:151-2). Today tailored Armani suits and Weston shoes are objects that play a tremendous role in present-day Congo, although in another segment of society.

Again, it can perhaps be objected that the designer clothes are not produced locally, but this is the case for many other museum objects. Thus, eg, the Tuareg collection in the Danish National Museum includes a large number of import products as the Tuareg have long purchased many utensils from their neighbours. Removing imported products would of course similarly leave many display cases empty in museums about our own past and present.

In other words, there is nothing wrong with the designer clothes themselves as representations of African culture apart from the fact that they will appear very un-African to European museum visitors. The power figures on the other hand $d o$ appear African, although the majority of the statuettes in museums were made in a period of extremely intense colonialsm and can be said to reflect CongoleseEuropean contact just as much as the Parisian garments do.

\section{THE NATURE OF THE THING}

As Hervik noted in Mexico, it is not only the unprepared museum visitor, but also the trained anthropologist who immediately interpret certain things in certain con- 
118 texts as foreign elements. This is because of what I call «the nature of the thing». This expression refers not to the meanings of specific objects, but to the way material objects are generally understood by humans, namely as evidential.

An object appears evidential in two ways: First it appears as if meaning is inherent in the object, although this meaning is actually ascribed by the beholder, in other words objects seem to have an inherent, unequivocal meaning. Secondly, they are viewed as evidence of something: The crown prooves the king's royal status, the souvenir testifies to the experiences of the trip, a stone in the shape of a finger is evidence of the existence of a Papuan cave full of powerful knowledge, the crocodile shoes of the sapeur are proof of his access to a Parisian power centre. ${ }^{8}$

When we perceive things like TV sets or Coca Cola bottles as being contradictory to Mexican leaf houses it is because we see television sets and Coke bottles as evidence of our own way of living, a busy life in large polluted cities, etc. The presence of these objects in foreign settings is often called "Coke-colonization", implying that the spread of certain mass-produced goods to every corner of the world automatically entails the spread of Western culture. It is as if the object somehow contains a particular way of living, as if watching TV and drinking Coke will change people's way of life in a certain direction.

It is true that today the same products are used all over the world. But, as Parkin has rightly stressed, Coke-colonization is of course nothing compared to real colonization with all its forced changes of government structures, educational systems, methods of production, etc.
(1993:85-6). What makes the objects seem so influential is that they appear as evidence of familiarity in a context of expected difference. This is important to the museum, being as it is a place for exhibiting the Other.

A museum is a house full of things and thus a house full of evidences. In the case of the ethnographic, historical or pre-historical museum it has so far been a house where one has met the Other in time and space, or rather met oneself through the image of the Other. Thus the museum object has been an evidence of otherness. The authority of the museum institution with its experts and technichal facilities, even add to the character of the object as evidence.

The museum object appears evidential despite the fact that museum displays are of course always results of an individual curator's choice of objects and form of presentation. The fact that the form of presentation is a crucial factor in creating the meaning and value of an object has been widely acknowledged in the museum world. This acknowledgement has been directly applied in recent exhibitions, deliberately drawing the attention of the audience towards the frame of the presentation (eg. Sjørslev 1991 and Vogel 1991).

The debate has centered on (re-)contextualization as constitutive of the meaning of a given object. Clifford brilliantly abstracts what he terms «the modern artculture system"; a historically specific cognitive model becoming manifest in museum classifications of certain objects as either "art" (i.e.regarded as unique, individual masterpieces) or "culture» (i.e.regarded as objects of a collective tra- 
dition) (1988:222-6). The contextualization of an artefact will determine its status in the system as either art or culture. Clifford uses as an example how moving the French impressionist paintings from Jeu de Paume to the Musée d'Orsay changed their status from unique timeless masterpieces to examples of the wider cultural-historical context of their time. In other words the paintings were implicitly re-classified from works of art to works of culture (ibid. 224-5).

The shift can also happen in the opposite direction as when, eg, Australian bark paintings are moved from the ethnographic museum to the art museum, and are thus reclassified from «culture» to «art».

However - although the institutional frame as well the catalogue texts assure the reader that bark paintings should be appreciated as art - they are still not considered quite as individual and original as the work of a contemporary white Australian painter. Being painted by an aboriginal these paintings somehow continue to be regarded as "culture», i.e.results of a collective tradition.

Likewise, the French impressionist paintings do not really lose their status of masterpieces, by being re-contextualized as cultural objects in Musée d'Orsay; to verify this one just has to note where the largest crowds of people are assembled in the display rooms.

Thus we see how evidential meaning «sticks» to the object despite its recontextualization. Admittedly, Vogel demonstrates how African objects such as a hunting net and a metal blade (originally used for bride price payments), can be presented as pieces of modern art by placing them prominently on a podium and focusing a spotlight on them (1991:196). But the category of modern art is basically defined as being uncertain and flexible. Other meanings are not created as easily as that; it will be hard to present the Armani suit as a power figure as evidence of African cultural traditions. ${ }^{?}$

No generalisations can be stated about the meaning of a thing when we see it in a certain context. It is not possible to tell the meaning of imported as well as locally made objects, unless one looks carefully into their roles in the local social world.

Europeans driving Japanese cars are not concerned with their "Japaneseness", as Japanese cars are very anonymous compared to other more life-style oriented cars such as, e.g., Citroên or BMW. The future archaeologist, however, might well interpret the presence in Europe of millions of Japanese cars in the last two decades of the 20 th century as evidence of a Japan-oriented mass cult. Consumption of sea weed and sushi dining among other groups within the European population might be said to have a lot more reference to Japan than the car, but will not be visible to the archaeologist.

These examples taken from a more familiar setting emphasize the difficulties we encounter in foreign contexts where the origin of a thing does not in itself give any clues to its meaning. As we have seen, the Congolese consumption of certain European products does stress the foreign origin of the objects, but within a local and long-existing conceptual framework, in which the meaning of imported clothes in many ways parallels the meaning of traditional power figures. The Papuans do not regard the imported products as fore- 
120 ign at all, but rather as manifestations of a local ancestoral knowledge that was temporarily lost. They use Egyptian statues in order to restore the knowledge of their ancestors, and they use the knowledge of their ancestors in order to get trucks and generators as well as dog's teeth and parrot feathers.

Although origin is thus not a significant characteristic for understanding the specific meaning of an object, it is however the defining criterium within a relatively new research field of the Ethnographic Department of the Danish National Museum. This research field concerns "cross-cultural encounters as they are reflected in local arts and crafts traditions». In other words this theme of culture contact is focused on collection of and research into material objects that show innovative incorporations of foreign elements. Examples of such objects are African toys made of recycled tins, or a Chokwe (Angola) throne from the last century made in the shape of a European chair, but with Chokwe-style carvings.

Collecting and exhibiting such objects is a way of creating awareness of the fact that people everywhere incorporate new styles and objects into their existing traditions. By focusing so clearly on innovation and exchange we thus moderate the way we have hitherto presented other cultures as isolated and stable wholes. Thus displaying these products of cross-cultural contact is a much needed counter-balance to the theory of Coke-colonization or mono-culturalism, illustrating - by the use of objects - that the world is not about to lose all cultural diversity.

However, we should be aware of two problems when using this criterium of «materialized cultural encounters». First it might be taken as evidence of an increasingly complex world in which people currently exchange ideas, objects, customs, etc. on a much wider scale than previously. But culture contact is not a new thing; people have always interacted in these ways, and pure cultures never existed.

Secondly, we should remember that by introducing the theme of culture contact in a museum context we are still operating first and foremost within our own ideational frame of prefigured and unreflected prototypical stereotypes about other cultures. By collecting and displaying products of contact we do not automatically create a truer description of the life of the people we want to represent or get any closer to the objects' meaning to these people. When using terms such as cultural contact or cultural complexity we discern two separate traditions meeting in the object. But, as we have seen, these two traditions may not exist for those who «mixed» them by making or using the object. Just as Danes are not much concerned with the South American origin of the potato when they cook, African children do not wonder about how the - now locally produced - tins they make toys of once originated in Europe. Only we may see these toys as a result of culture contact, because tins appear essentially European to us.

Whatever types of objects are collected and exhibited they will either fit into or not fit into the prototypical image of that particular place. Through the display of objects the curator will be able to affirm or moderate some of these expectations, but will constantly be limited by the evidential meaning of a particular object in a particular context in the audience's view 
as well as in the researcher's own view. Whether we should exibit the Armani suit or the power figure in an African exhibition is a matter of choice in the specific situation. It is crucial, however, to clarify what would seem to be the evidential meaning of the object to the audience, and use this knowledge as a starting point for the image or story of the other that is constructed in the exhibition.

Today museums are no longer a Western phenomenon alone. Today we are being represented in faraway museums, as someone else's Other. Thus a Malaysian museum in a recent exhibition about body mutilations displayed photographs of Western "urban primitives» next to pictures of more traditional "primitives», in the form of tribal peoples from all over the world. Their common piercing rings and tatoos may be viewed by the Malaysian museum visitor as evidence of a common misfortune of those who have not yet emerged from tribalness and Westerners who are about to enter it, as a result of cultural decadence caused by extreme individualism. This is of course my guess about how such an exhibition is interpreted by Malaysians, but it might still illustrate how far the images we make about the Other will often come from the selfexperience of that other.

\section{NOTES}

* This essay was given in a somewhat different form as a lecture for Museumshøjskolen (Copenhagen, March 1995). The theme of the day was the question of whether material objects can be used as evidences of a certain culture.

1. "Mermaid" is an indigenous translation for faifai, a term that refers to non-human spirits living below the surface of the ground and the rivers. In this particular case the word refers to a cow.

2. I have left out the name of the mountain, as such names belong to the clan that own the land and are normally kept secret from strangers.

3. The local term nao which is used for white people includes Caucasians and Asians.

4. See eg. Lattas (1992) for a similar case where the Kaliai of West New Britain speak of the white people as the ones who have the knowledge to make proper things "come up" whereas the Kaliai, whose ancestors first had access to this knowledge, now only know how to make sago palms "come up".

5. The Powerhouse activities ended when one of the participants went mad. Later his father burned down the house with all the books inside so I have not seen the books myself.

6. See Ekholm Friedman 1991 Chapter 3, for a discussion of the principle of externality both as it has been expressed in different periods of Congolese history, and as a socially determined model of person and society in clan-based societies in general. See also Friedman 1994:152-3) for an overview of the "internal logic» of this principle.

Ekholm Friedman 1994 (esp. chapt. 3) gives a detailed description of the principle of fetishism and external force in present-day Congo, where e.g.marijuana and Western medicine are used as modern fetishes.

7. It should be remembered that here I am concerned with the cultural models of the person. In everyday Congolese practice much ambivalence and doubt is of course created by the fact that the best appearance does not always equal the most powerful position. In the West people have also spent time and money on their looks while at the same time stating that true beauty comes from the inside.

Nowadays it seems that there are strong tendencies in Europe and America for people to invest 
122 increasing amounts of money, time, and suffering in personal appearance. Whether these tendencies reflects a shift in cultural models bringing us nearer to the Congolese, is a matter that deserves attention, but this is not the place for such discussions.

8. The way I use the expression "nature of things" as a proces of unconscious human ascription of meaning to objects that appear to hold this meaning independently is equivalent to Miller's term «objectification» (1987) and to Parkin's term «animated materiality" (1993:96).

9. See Errington 1994 for a shrewd analysis of the category of so-called "primitive art", showing that the prototypical object of this category is a wooden African anthropomorphic image, that has been stripped for all its soft materials, looking somehow spiritual and like something that "could have influenced Picasso and Vlaminck", as well as being of a portable size. These "criteria" are of course not explicitly stated or even realized by those collecting and exhibiting primitive art, and this example shows once again how immediately and unreflectively objects are being interpreted.

\section{REFERENCES:}

Clifford, James. 1988. The Predicament of Culture. Twentieth-century ethnograhy, literature, and art. Cambridge, Mass.: Harvard University Press.

Ekholm Friedman. 1991. Catastrophe and Creation. The transformation of an African culture. Chur: Harwood Academic Publishers.

Ekholm Friedman. 1994. Den magiska väldsbilden. Om statens frigörelse frän folket i folkerepublikken Kongo. Stockholm: Carlssons.

Errington, Shelly. 1994. What became Authentic Primitive Art? Cultural Anthropology 9(2): 201226.

Friedman, Jonathan. 1994. Globalization and Localization. + The Political Economy of
Elegance. In: Cultural Identity and global Process. London: Sage.

Hervik, Peter. 1992. Learning to be "Indian». Aspects of new Ethnic and Cultural Identity of the Yucatec Maya. Folk 34: 63-80.

Lattas, Andrew. 1992. Skin, personhood and redemption: the double self in West New Britain cargo cults. Oceania 63: 27-54.

MacGaffey, Wyatt. 1991. Art and Healing of the Bakongo commented by themselves: Minkisi from the Laman Collection. Stockholm: Folkens museum-etnografiska.

Martin, Phyllis. 1994. Contesting Clothes in Colonial Brazzaville. The Journal of African History 35(3): 401-426.

Miller, Daniel. 1987. Material Culture and Mass Consumption. Oxford.

Parkin, David. 1993. Nemi in the modern world: return of the exotic? Man 28(1):79-99.

Sjørslev, Inger. 1991.Communicating Objects. Towards a Theory of Exhibition Language. Folk 33: 5-25.

Vogel, Susan. 1991. Always True to the Object, in Our Fashion. In: I. Karp and S. Lavine: Exhibiting Cultures. The Poetics and Politics of Museum Display. Washington: Smithsonian Institution Press.

Bente Wolff, anthropologist. Field research on material culture for the National Museum of Solomon Island and on oral history among the Mekeo people of Papua New Guinea.

Adr: University of Copenhagen, Department of Anthropology, Fredriksholms Kanal 4, DK-1220 Copenhagen K, fax $+45-35323465$ Also attached to the Etnographic Department of the National Museum of Denmark, fax +45-33473320 e-mail:Es-bw@palais.natmus.dk 